\title{
Article
}

\section{Nutritional quality, cost and availability of gluten free food in England}

Soon, Jan Mei and Hopkins, Sarah

Available at http://clok.uclan.ac.uk/29650/

Soon, Jan Mei ORCID: 0000-0003-0488-1434 and Hopkins, Sarah (2019)

Nutritional quality, cost and availability of gluten free food in England. British Food Journal, 121 (11). pp. 2867-2882. ISSN 0007-070X

It is advisable to refer to the publisher's version if you intend to cite from the work. http://dx.doi.org/10.1108/BFJ-09-2018-0607

For more information about UCLan's research in this area go to

http://www.uclan.ac.uk/researchgroups/ and search for < name of research Group>.

For information about Research generally at UCLan please go to http://www.uclan.ac.uk/research/

All outputs in CLoK are protected by Intellectual Property Rights law, including Copyright law. Copyright, IPR and Moral Rights for the works on this site are retained by the individual authors and/or other copyright owners. Terms and conditions for use of this material are defined in the policies page.

\section{CLoK}

Central Lancashire online Knowledge www.clok.uclan.ac.uk

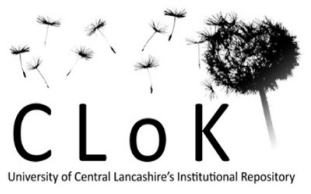


3 Abstract

Purpose: Coeliac disease is a life-long condition requiring strict adherence to a gluten free diet. Due to wide claims of availability and lower costs of gluten free food (GFF) and Clinical Commissioning Groups (CCGs) in England needing to save costs, access to prescriptions for patients with coeliac disease (CD)is being limited in England. The purpose of this study is to investigate the availability and cost of GFF in an area where patients with coeliac disease have restricted access to prescriptions and to assess the nutritional composition of GFFs available in comparison with foods containing gluten.

Methodology: Eight food categories that were representative of a range of commonly purchased GFFs were selected. Availability and cost of cheapest and most expensive branded and non-branded GFFs and gluten containing equivalents were surveyed at physical stores $(n=19)$ and online stores $(n=8)$. The nutritional composition of some of the widely available GFFs identified $(n=190)$ and comparable foods containing gluten $(n=218)$ were calculated using MyFitnessPal.

Findings: None of the budget stores or corner shops surveyed stocked any of the surveyed cereal-based GFFs. Online stores had more availability than physical stores, however there was no significant difference in cost. Gluten free foods cost on average 2.18 times more than food containing gluten. When making nutritional comparisons with gluten-containing food, protein content was lower across $55 \%$ of GFF categories. There was significantly less sugar in gluten free (GF) brown bread, crackers, and wholegrain pasta compared with those containing gluten. Another main finding was GF ready-meals contained significantly less salt than ready-meals containing gluten.

Originality: Limited resources and perceived wide availability of gluten-free products resulted in reduced GF prescriptions to patients in England. The findings in this study revealed that there is no availability of cereal-based GFFs in budget stores, high cost and limited access to prescriptions can influence adherence to a gluten free diet and is most likely to affect patients from deprived groups. This study recommends that the prescription of gluten free food to patients with CD should be continued.

Keywords: availability; coeliac disease; cost; gluten-free; nutrition 


\section{Introduction}

Coeliac disease (CD) is a systemic immune-mediated disorder activated by gluten and related prolamines ingestion in genetically susceptible individuals. It is characterised by the presence of CD specific antibodies and human leukocyte antigen (HLA)-DQ2 and HLA-DQ8 (Husby et al., 2012; Nelsen, 2002). The prevalence of CD in the Western World is estimated at approximately $1-2 \%$ of the population and is considered an autoimmune disease affecting both adults and children (Simón et al., 2017). In the UK, $0.24 \%$ of the population (approximately 150,000 people) are clinically diagnosed with CD, however seroprevalence is $1-1.6 \%$, and prevalence is increasing (Crooks, 2016). Gluten is an insoluble storage protein found in wheat, rye, barley and triticale, and is made up of peptides gliadin and glutenin (Wieser, 2007). These peptides are used in many foods to give them structure and improve palatability (Gobbeti and Gänzle, 2013), however, when a patient with coeliac disease ingests gluten, an immune reaction promotes secretion of high volumes of proinflammatory cytokines and inflammatory mediators which attack the intestinal villi, causing it to become inflamed (Mazzarella, 2015). Inflammation reduces the surface area of the villi making it difficult to effectively absorb nutrients (Buttriss, 2002). Left untreated, CD can result in villous atrophy, where the intestinal villi have completely eroded causing malabsorption (Theethira et al., 2014). Study found that $43 \%$ of CD patients exhibited persistent villous atrophy on a follow up biopsy, which was caused by non-adherence to a gluten-free (GF) diet, thought to be a consequence of social differences due to access/or education (Lebwohl et al., 2014). The only treatment available for individuals suffering with CD or associated complications is to follow a strict life-long, GF diet. This consists of foods that are naturally GF, and manufactured foods such as bread and pasta where substitutes replace wheat (e.g. corn, rice or potato starch) (Ciacci et al., 2015). Products containing less than 20ppm are considered GF by the Codex Alimentarius (FAO/WHO, 2015). Initiation of the GF diet has been found to restore integrity of the intestinal wall, and improve symptoms and deficiencies of $\mathrm{CD}$, however, certain nutritional limitations exist (Barone et al., 2016; Theethira et al., 2014).

Adhering to a GF diet is difficult and takes a lot of self-control. Other factors influencing adherence include availability, cost, nutritional quality and access to gluten-free food (GFF) on prescription (MacCulloch and Rashid, 2014; Hall et al., 2013). It has previously been demonstrated that GFF cost on average 4.1 times more than food containing gluten (FCG) (Burden et al., 2015). Missbach et al. (2015) observed that GF foods were significantly 
higher in cost than similar foods containing gluten (range $=205 \%-267 \%$ ) in Austria. Previous studies have also demonstrated limited availability of GF foods, with no availability of cereal-based GF staples in budget stores and corner shops. A persistent finding is the higher cost of GFFs when making comparisons with FCG (Singh and Whelan, 2011; do Nascimento et al., 2014; Fry et al., 2018). The cost of food is an important factor which influences food choice (Lennernäs et al., 1997). The socioeconomic status of patients may determine which stores they shop in (Ellaway and Macintyre, 2000), and so the lack of availability in budget stores and corner shops may affect adherence to a GF diet. This may particularly burden patients who have no or limited access to GF foods on prescription (Muhammad et al., 2017).

Studies focussing on analysing the nutritional composition of GFFs have found they contain low levels of essential micronutrients such as iron, folic acid, calcium, potassium, zinc and magnesium (Thompson, 2000; Estévez et al., 2016; Missbach et al., 2015). High fat content has been another observation. Studies have demonstrated that GF breads have significantly more fat than breads containing gluten (Kulai and Rashid, 2014; Fry et al., 2018). Studies have also reported lower levels of protein and fibre content when compared with similar gluten containing foods (do Nascimento et al., 2014; Miranda et al.,2014; Missbach et al., 2015. Meanwhile Fry et al. (2018) found fibre content to be significantly higher in GF items such as white and brown bread whilst protein was found to be lower in GF products compared to gluten containing foods.

Gluten-free foods have been available on prescription to patients with CD since the late 1960's (Department of Health, 2017), however, due to wider availability and reduced cost, as of $5^{\text {th }}$ December 2016, the National Health Service (NHS) made budget cuts, and the Clinical Commissioning Groups (CCGs) in England changed their policies on GF prescriptions (Coeliac UK, 2019a). CCGs are groups of general practices (GPs) that come together in an area to commission the best services for patients and the population. CCGs buy services for the local community from any local service provider that meets the NHS standards and cost and aims to provide better care for patients (NHS, 2019). This resulted in $40 \%$ of 207 local CCG's restricting or completely stopping GF prescriptions (Coeliac UK, 2019a). The rationale of wider availability and lower costs of GF foods conflicts with evidence found in previous research (Singh and Whelan, 2011; do Nascimento et al., 2014; Burden et al., 2015; Fry et al., 2018; Hanci and Jeanes, 2018). 
Before CCGs made policy changes, $90 \%$ of patients with CD relied on prescriptions for GFF (Robins et al., 2008), this offered fundamental support to those on a low income, benefits, and the elderly. Furthermore, Kinsey et al. (2008), found that prescription GFFs were higher in non-starch polysaccharides (NSP), calcium and iron compared with commercially available GF foods. However, since the studies conducted by Robins et al. and Kinsey et al. in 2008, more recent studies have found a lack of availability of GF foods and higher costs associated with such items. Therefore, the removal of GFF prescriptions is likely to affect the nutritional adequacy of a patient with coeliac disease GF diet, which could lead to health complications. A combination of restricting prescriptions, high cost of GFF and limited availability could potentially influence adherence to a gluten free diet (Coeliac UK, 2019.b; Estévez et al., 2016). Health risks associated with non-adherence include osteoporosis, osteopenia, infertility, anaemia, vitamin D deficiency, increased risk of fractures and cancer (BDA, 2015; Kinsey et al., 2008).

Stopping access to GFFs for primary care patients has recently been rejected by the government, and the Department of Health and Social Care (2018) has decided to restrict gluten-free prescribing to breads and flour mixes only (NHSCC, 2018). However, CCGs have the ability to control their own policies and can ultimately decide how much food can be prescribed, and who is entitled to it. Currently, patients with coeliac disease living in Greater Preston still have no access to GF prescriptions and until regulations have been developed and formally agreed by Parliament, the CCG for Greater Preston do not have to make changes to current policy. With increasing prevalence of $C D$ and restrictions to prescriptions for patients with coeliac disease, the purpose of this study was to assess the availability of GFF and compare cost and nutritional quality with FCG in an area where GF prescribing is currently on hold and may be limited once new prescription regulations have been implemented.

\section{Methodology}

\section{Store selection}

The area chosen for assessment was Greater Preston situated in North West England, as this was one of the areas where prescriptions for GFF were withdrawn on $5^{\text {th }}$ December 2016 (Coeliac UK, 2019a). Stores such as regular stores, quality stores, budget stores, health food shops, convenience stores and corner shops, as previously categorised by Singh and Whelan (2011) were visited. The availability and cost of branded and non-branded GFFs 
were surveyed as were similar FCG at different stores after receiving consent from the store managers.

Food categories

An itinerary of eight food items were chosen and were representative of a range of commonly purchased GFFs (do Nascimento et al., 2014; Fry et al., 2018). Food items were categorised as biscuits, breads, cakes, cereals (breakfast), crackers, flour, pasta and readymeals were analysed for availability and cost. Additionally, similar categories of FCG were also analysed for cost, so a direct comparison could be made.

\section{Survey}

Stores were surveyed between November 2017 and January 2018. Availability was measured by counting how many different GF brands were stocked in each of the eight food categories in all stores visited, and a photograph of the same stock was captured on camera by smart phone. The cost of the cheapest and most expensive item was recorded, and for items with wide availability, the cost of the cheapest and most expensive branded and none branded foods was recorded. The same method was adopted for similar FCG and all costs were captured by camera using a smart phone. Package weight was not used as covariate as food comparisons may be weighted differently hence costs were calculated as pence $(£)$ per $100 \mathrm{~g}$.

\section{Online stores}

Appropriate keywords were entered onto a google search engine to find stores with availability of GFF that delivered to homes in Greater Preston. Nine stores were selected and represented online regular stores, quality stores, health food stores and stores specialising in GF foods. This was to achieve a comparable analysis of online store availability and cost. The stores selected were those that landed on the first google result page, as this is where $95 \%$ of websites receive most visits (Brafton, 2013). The eight GFFs categories were separately entered onto the search bar of each online store and listed foods available were noted. The cost in pence per $100 \mathrm{~g}$ of the cheapest and most expensive foods was recorded, and for items with wide availability, the cost of the cheapest and most expensive branded and none branded foods were recorded (Hanci and Jeanes, 2018). 
174 Nutritional quality of GFFs and FCG were calculated using MyFitnessPal (MyFitnessPal.com, 2015). This involved foods from the eight food categories, however bread was separated into white and brown, flour into white and wholemeal, and pasta into white and wholegrain so that comparisons could be made with previous research (Miranda et al., 2014; Fry et al., 2018). Food items were entered into MyFitnessPal search bar and products were selected if listed. This app was selected as the nutritional data available from MyFitnessPal contained information obtained from product labels which should be declared according to European Union legislation 1169/2011 (EUFIC, 2011). These mandatory nutrients (per 100 grams) included energy, protein, carbohydrates, sugars, total fat, saturated fat and salt, which were systematically collected for GFFs and similar FCG. Additionally, fibre content was obtained where data was available and any food items, which could not be found, were excluded from analysis.

\section{Statistical Analysis}

188 Statistical analyses were performed using SPSS version 24 (IBM Corp, 2016). Normal Q-Q 189 plots and Shapiro-Wilk test of normality $(p>0.05)$ were used to assess if data deviate from 190 a normal distribution. Independent samples t-tests were used to compare the availability 191 and cost of GFFs at online stores and stores located around Greater Preston, and to 192 compare the average nutritional content of GFF and similar FCG across all product 193 categories. Equal variances were assumed if the Levene's test for homogeneity of variance was non-significant ( $p>$.05). A one-way analysis of variance (ANOVA) was performed to observe differences in the cost and availability of GFF compared with FCG across all store categories and independent samples $t$-tests were applied to make cost comparisons between two store categories. $p \leq 0.05$ was considered statistically significant.

\section{Results}

200 A total of 27 stores were investigated, of which 19 were located around Greater Preston and eight online stores that delivered within the Greater Preston area. Out of the 27 stores visited, seven (25.9\%) stocked no GFF, with the remaining 20 (74.1\%) stocking at least four categories of GFF. Across the seven different store types, 2,780 GF foods were identified (crossovers occurred), 1,800 of which were available online, and 980 stocked in physical stores around Greater Preston). The number of GFFs available from each food category per store type is shown in Table 1. A one-way ANOVA revealed food category had a significant effect on availability except for flour $(p=0.156)$. Store types stocking one or more GFFs 
from every food category included online, regular, quality and health food shops (100\%), with convenience stores stocking on average $87.5 \%$. In general, budget stores and corner shops stocked no cereal-based GFFs, whilst online stores were found to stock the widest range. Of the physical stores, regular and quality stores had the highest availability and all stores stocked at least one GFF item from each food category with the exception of convenience stores, that carried no stock of GF ready meals.

Insert Table 1 here

A one-way ANOVA revealed that store type had a significant effect on cost $(f(4,1008)=$ $12.40, p<.001$, eta ${ }^{2}=.047$ ). To explore the location of significance, a Tukey's HSD post hoc was conducted, which revealed some GFFs significantly differed in cost depending on type of store (Table 2). For example, the average cost of cereals was significantly more expensive in health food shops than regular stores $(1.10$ and 0.67 pence per $100 \mathrm{~g}$ respectively, $p<.001$ ). The cost of 1,047 GFFs within the eight food categories (cheapest and most expensive items) were compared with 750 similar foods containing gluten. Only items with A one-way ANOVA revealed cost had a significant effect on whether or not food contained gluten $(f 1,1781) 870.299, p<.001$, eta $\left.{ }^{2}=.328\right)$. Independent $t$-tests showed that all GFFs were significantly more expensive than FCG (Table 2), costing on average 2.18 times more, with bread representing the highest price difference $(62.2 \%)$ and ready meals the lowest price difference (38.89\%). GF bread costs an average 2.65 times more than GC bread products.

Insert Tale 2 here

A comparison of energy and macronutrients of widely available forms of GFFs $(n=190)$ and a gluten containing equivalent $(n=218)$ from each food category was analysed using independent t-tests and results are displayed in Table 3. Across all food categories, the nutritional content of GFF compared with a gluten free equivalent did not significantly differ between biscuits, cakes and cereals $(p>0.05)$. The only significant difference in energy was observed in flour, where GF white flour contained significantly more than white flour containing gluten $(p=0.05)$. In the breads, crackers, flour and white pasta categories, the average protein content in GF foods was significantly lower than their gluten containing equivalents $(p<0.05)$. When compared with FCG, gluten free flours and white pasta 
contained significantly more carbohydrates $(p<0.05)$, although less carbohydrates were observed in GF white bread $(p=0.001)$.

There was significantly less sugar in GF brown bread, crackers, and wholegrain pasta compared with those containing gluten $(p<0.05)$. Another finding was GF ready-meals contained significantly less salt than ready-meals containing gluten $(p=0.002)$. When comparing the gluten containing bread categories, more total fat was found in both GF brown and white bread ( $p=.02$ and $p=.007$ respectively). Interestingly, GF white bread was found to contain significantly more fibre than white bread containing gluten $(7.15 \pm 2.13$ and $2.72 \pm 1.46 \mathrm{~g} / 100 \mathrm{~g}$ respectively, $p<.001)$, however, white GF pasta contained less fibre $(p<.001)$. In general, protein content was found to be significantly lower in $55 \%$ of GFF compared with FCG.

Insert Table 3 here

\section{Discussion}

\section{Availability of gluten-free food}

The present study identified 2,780 GFFs within eight food categories, across seven store types, demonstrating availability of a wide range of products, however availability varied significantly between store type $(p<.001)$. This could be attributable to the difference in store sizes which was not factored into the analysis. Overall, online stores offered the widest range of GFF compared to physical stores, which was also an observation made by Burden et al. (2015) and could be due to several reasons. Online stores run their operations from warehouses which have the capacity to carry large volumes of stock, their profitability margins are likely to be high due to lower running costs, their logistics are very efficient, for example fast turnaround between order time and delivery time; and marketing campaigns reach out to new customers (Fernie et al., 2010). These may all contribute to increased availability to meet consumer demand. The wider range of GFF available online offers consumers more choice and is a service which may help CD patients who have limited mobility. However, access is only available to those who are computer literate, have access to the internet and can afford delivery costs (Webb, 2013).

\section{Of all physical stores surveyed, regular stores carried the most stock of cereal-based GFF} followed by quality stores, health food shops and convenience stores, with budget stores 
and corner shops stocking none. This is similar with previous findings, however the present study observed a wider choice, for example, Singh and Whelan. (2011), reported less availability of GF breads in regular supermarkets than the present study. Furthermore, Burden et al. (2015), observed the highest availability of GFF in quality supermarkets, and although there was more availability in quality stores in the present study, the highest availability was found in regular stores. Similarly, Hanci and Jeanes (2018) reported that GF food availability has increased in premium and online stores. This could be due to manufacturers responding to increasing demand of GFF due to the increasing prevalence of $\mathrm{CD}$ and associated complications. There has also been a growth in supermarkets own-label GFFs (Smith, 2010), which may offer further explanation as to why there is a wider range of GFF available than previously reported. With CD on the increase, future studies may see an increase in availability, particularly in stores with own-brand labels.

Although the present study supports a wider range of GF items available than in recent years, it also demonstrates availability is poor in budget stores and corner shops, a consistent finding in previous studies (do Nascimento et al., 2014; Hanci and Jeanes, 2018; Singh and Whelan, 2011; Burden et al., 2015). Budget stores may choose not to stock cereal-based GFF because offering them for sale at prices their shoppers are accustomed to may not be profitable. Gluten-free ingredients are expensive, and there are additional costs incurred during manufacturing such as dedicated GF factories, dedicated areas within factories, and investment in new technologies (Coeliac UK, 2016). Therefore, suppliers of GF foods may not have the flexibility to negotiate low prices and until ingredient and production costs of GFFs reduce, it is unlikely that budget stores will stock them.

A wider range of GFFs offer patients with coeliac disease more options, allowing them to choose food based on personal preferences which can contribute to adhering to a GF diet (Wright, 2017). However, this only applies to patients with higher disposable expenditures. Gluten-free food options remain limited for patients shopping on a budget, or are unable to access larger stores, or have no internet access. This study has demonstrated there are more cereal-based GFF items available than previously reported, which supports the NHS's principle of wider availability of GFF, however, availability remains poor in budget stores and corner shops, and until all stores stock $100 \%$ of common foods that are GF then availability should be considered limited. 
The present study found GFF within eight food categories presented significantly higher prices than FCG, costing on average 2.18 times more (118\% price difference). This could be attributable to the use of more expensive grains in replacement of wheat (Jnawali et al., 2016), or the usage of innovative processing techniques to improve the nutritional quality and organoleptic properties of GFF (Padalino et al., 2016). Therefore, it is understandable that they are costlier than FCG.

A difference in cost of GFF and FCG has been a consistent finding, however the price difference in the present study is lower than previously reported (Singh and Whelan, 2011; Lee et al., 2007; Stevens and Rashid, 2008). In the UK, Burden et al. (2015) found GFF cost on average 4.1 times more than FCG. More recently, Fry et al. (2018) surveyed websites of four leading UK supermarkets as well as a leading online food retailer and found that 10 common GFFs were on average $159 \%$ more expensive than FCG. The high cost of GFF is a key influential factor for adherence to a GF diet (Muhammad et al., 2017). This can be supported by responses from a patient survey which revealed that $82 \%$ of 1,000 primary care patients revealed it was harder to manage their diet due to GF foods costing more than regular foods (BSNA, 2013). Therefore, due to the CCG ceasing prescriptions for GFF in Greater Preston, local patients with coeliac disease who have heavily relied on GF prescriptions may find it difficult to adhere to a gluten free diet due to affordability. Furthermore, patients have been found to be more likely to adhere to a GF diet when obtaining their food on prescription (Hall et al., 2013).

\section{Nutritional content of gluten-free food}

The present data shows that $75 \%$ of GFF across all categories displayed differences in nutritional composition compared with FCG. A key finding was a significantly lower protein content in GF bread, crackers, flour and pasta compared with gluten-containing equivalents, with bread and flours having more than two times less protein. Gluten is an important constituent for food manufacturers, as its major storage proteins gliadin and glutenin gives

340 food elasticity and structure, producing an end-product which is visually appealing and 341 highly palatable (Gobbetti and Gänzle, 2013). Manufacturers use a wheat substitute, such

342 as corn and rice flour and add proteins, gums and emulsifiers to substitute gluten to 343 formulate GFF to represent FCG (Padalino et al., 2016). Rice flour is an inexpensive widely 344 available ingredient which is commonly used to formulate GF breads (Sandri et al., 2017), 
however the protein content in rice flour is almost $50 \%$ less than wheat flour (Lásztity, 1983).

Lower protein content in GFF compared with FCG has been a consistent finding in previous research (Miranda et al., 2014; Fry et al., 2018; Wu et al., 2015; do Nascimento et al., 2014; Missbach et al., 2015). This has resulted in food technologists investigating the reformulation of GFF with pseudo-cereals, which naturally contain high amounts of essential amino acids (Drzewieki et al., 2003). Gambus et al. (2002) found that replacing corn starch with amaranth flour in the re-formulation of GF bread increased its protein content by $32 \%$ with no effect on its sensory quality. A more recent study by Alvarez-Jubete et al. (2009), found that formulating GF bread with $50 \%$ rice flour or $50 \%$ potato starch with amaranth, buckwheat or quinoa flour increased protein, fibre, calcium, iron, vitamin $E$ and polyphenol contents. Therefore, the use of pseudo-cereals in the formulation of GF foods will enhance its protein content and overall quality, providing an improved product for the consumer. Although some manufacturers have made advances in improving quality of GFFs (Wang et al., 2017), their availability on the market may be limited. This could be due to the extra cost of ingredients and the advanced technology needed in their re-formulation. Also, certain food manufacturers may choose least expensive ingredients to keep production costs at a minimum to keep costs down for consumers.

Carbohydrates are an important source of energy, and over a third of the diet should consist of starchy foods (NHS Choices, 2017). The present study found that flours and white pasta had significantly more carbohydrates than their gluten-containing equivalents. This could be due to the poor protein content in GF flours that are also used to produce pasta. When making comparisons with breads however, a significantly lower carbohydrate content was found in GF white bread compared with gluten-containing equivalents. This is an interesting finding, considering starch ingredients such as corn, cassava, potato and rice are commonly used as main ingredients or partial substitutes in GF breads. Additionally, gel forming starches such as pregelatinized starches and gums act as stabilising agents to achieve structure, texture and crumb in the absence of gliadin and glutenin (Horstmann et al., 2017). Previous studies have observed no significant differences in GF breads when comparing them with breads containing gluten (CG) (Kulai and Rashid, 2014; do Nascimento et al., 2013). This further supports the notion of application of better-quality ingredients during reformulation of GF white bread. 
The present study found that ready-meals containing gluten had over $50 \%$ more salt than GF ready-meals. This could be due to GFF manufacturers attempting to meet salt targets set by the Department of Health (DH, 2014). In 2004, the World Health Organisation (WHO) reported that people were consuming too much salt (9-12g/day) and set a global goal to reduce salt intake to $<5 \mathrm{~g} /$ day by 2025 (WHO, 2016). This prompted governments to design salt-reduction initiatives, and the food industry was asked to voluntarily reformulate salt content in foods as an attempt to improve public health (DH, 2014; FSA, 2008; WHO, 2004). As the production of GF ready meals is relatively recent, manufacturers can formulate foods with less salt without the consumer being affected. This may offer further explanation as to why GF ready-meals contained less salt compared to GC ready-meals.

The present study found that GF white pasta contained significantly less fibre than white pasta CG. This could be due to the removal of cereals, which can leave food with a high starch and low fibre content (Saturni et al., 2010). However, a key finding in the current study was significantly more fibre in GF white bread than white breads CG. This could be an outcome of the re-formulation of GF breads with pseudo-cereals to improve overall quality. For example, when Gambus et al. (2002), replaced corn starch with amaranth flour in GF bread, a $152 \%$ increase in fibre was observed. Furthermore, buckwheat flour has been found to improve nutritional quality of bread as well as improve its viscosity due to its high fibre content (Mariotti et al., 2013). Similar findings were reported by Fry et al. (2018), however, do Nascimento et al. (2014), found significantly lower fibre content in GF bread compared with bread CG. Therefore, based on results in the present study and by Fry et al. (2018), higher fibre content in UK GF white breads may be attributable to several factors; more manufacturers are re-formulating their GF breads to achieve a better-quality product; and GFF manufacturers may be responding to new government dietary recommendations published in 2016 regarding daily increase of fibre from $18 \mathrm{~g}$ a day to $30 \mathrm{~g}$ a day (PHE, 2016). Total fat content of GF breads in the present study was significantly higher than bread CG, which supports previous findings (Fry et al., 2018; Kulai and Rashid, 2014). This could be attributable to the addition of fats during formulation to create consistency, increase volume and reduce staling (Mancebo et al., 2017).

\section{Limitations}

There were several limitations for the present study. Firstly, nutritional composition of food was not obtained via direct chemical analysis. Instead, data was obtained from 
'MyFitnessPal', which is an application that obtains nutritional information from manufacturers' labels. Only selected GFF $(n=190)$ and FCG $(n=218)$ products were analysed. Secondly, a comparison of micronutrients in GF foods and foods containing gluten could not be investigated using the method adopted due to micronutrient contents on labels not being a mandatory requirement under current (EU) legislation 1169/2011 (FSA, n.d.). Direct chemical analysis is the only viable way to acquire micronutrient composition of foods. Thirdly, the price and nutritional content of all food analysed was based on $\mathrm{g} / 100 \mathrm{~g}$ and serving sizes have not been factored in to the analysis. Fourth, surveillance of foods in physical stores was based on observations of items which were displayed on the shelves, and any foods which had not been replenished may have been missed. The authors also recommend that the full range of GF breads and the price difference between types of GF bread in comparison with regular equivalents should be further studied. Finally, the sample size of stores and surveyed GFFs were limited to 27 stores within the Greater Preston area.

\section{Conclusion}

The present study has shown wider availability of cereal-based GFF, however access remains poor in budget stores and corner shops which are reported to be frequented by people on lower incomes. The price of GFF remains significantly high compared with FCG, which has been shown to affect some patients' adherence to a GF diet. Nutritional quality has improved based on previous research, and advantages were observed in fibre content, however, protein quality was significantly lower in $55 \%$ of GFFs analysed, and a higher fat content was found in breads. With increasing prevalence of $C D$, a demand for more GFFs may see manufacturers reduce their prices further as the market becomes more competitive. This is quite promising, however, ingredients equal in quality to FCG may be compromised to keep production costs down which could result in larger disparities in nutritional quality. In view of restrictions to GFF prescriptions, further longitudinal studies are required to evaluate the true impact that limiting access to GFF will have on health and adherence across all population groups. Therefore, full prescriptions for GF food should still

444 be available for primary care patients with $C D$ and should remain until availability, accessibility, price and nutritional content of GF food is improved.

\section{References}

448 Alvarez-Jubete, L.A., Arendt, E.K. and Gallagher, E. (2010), "Nutritive value of pseudocereals 449 and their increasing use as functional gluten-free ingredients", Trends in Food Science \& 450 Technology, Vol. 21, pp. 106-113. 
Barone, M., Della Valle, N., Rosania, R., Facciorusso, A., Trotta, A., Cantatore, F.P., Falco, S., Pignatiello, S., Viggiani, M.T., Amorusso, A., De Filippis, R., Di Leo, A. and Francavilla, R. (2016), "A comparison of the nutritional status between adult celiac patients on a long-term, strictly gluten-free diet and healthy subjects", European Journal of Clinical Nutrition, Vol. 70, No. 1, pp. 23-27.

Brafton (2013). 95 Percent of web traffic goes to sites on page 1 of Google SERPS [Study]. Available at: https://www.brafton.com/news/95-percent-of-web-traffic-goes-to-sites-onpage-1-of-google-serps-study/ [Accessed 11 April 2018].

British Dietetics Association (BDA) (2015), Policy Statement: Gluten Free Food on Prescription. Available at:

https://www.bda.uk.com/improvinghealth/healthprofessionals/policy statement gluten free food on prescription [Accessed 17 April 2018].

BSNA (2013). The impact of the restrictions to gluten-free prescription foods on people with Coeliac Disease: Report of Findings. British Specialist Nutrition Association. Available at: https://bsna.co.uk/uploads/files/Report-on-Impact-of-Restrictions-to-Gluten-FreePrescription-Foods.pdf [Accessed 15 April 2018].

Burden, M., Mooney, P. D., Blanshard, R. J., White, W. L., Cambray-Deakin, D. R and Sanders, D. S. (2015), "Cost and availability of gluten-free food in the UK: in store and online", Postgraduate Medical Journal, Vol. 91, No. 1081, pp. 622-626.

Buttriss, J. (2002). Adverse Reactions to Food. Oxford: Blackwell Science.

Ciacci, C., Ciclitira, P., Hadjivassiliou, M., Kaukinen, K., Ludvigsson, J.F., McGough, N., Sanders, D. S., Woodward, J., Leonard, J. N. and Swift, G. L. (2015), "The gluten-free diet and its current application in coeliac disease and dermaititis herpetiformis. United European Gastroenterology Journal, Vol. 3, No. 2, pp. 121-135.

Coeliac UK, 2016. Campaigning on the cost of gluten-free. [online] Available at:

<https://www.coeliac.org.uk/about-us/news/campaigning-on-the-cost-of-gluten-free/ > [Accessed 14 April 2018].

Coeliac UK. (2019a). Prescription policies. Available at: https://www.coeliac.org.uk/glutenfree-diet-and-lifestyle/prescriptions/prescription-policies/ [Accessed 16 July 2019].

Coeliac UK. (2019b). Gluten-free product certification. Available at:

https://www.coeliac.org.uk/food-industry-professionals/the-crossed-grain-symbol/ [Accessed 16 July 2019].

Crooks, C. (2016). Epidemiology of coeliac disease. Available at: https://www.coeliac.org.uk/ [Accessed 28 March 2018].

Department of Health (DH), 2014. Responsibility Deal Food Network - New salt targets: F9 Salt Reduction 2017 pledge \& F10 Out of Home Salt reduction pledge. Available at: http://webarchive.nationalarchives.gov.uk/20180201175712/https://responsibilitydeal.dh.go v.uk/responsibility-deal-food-network-new-salt-targets-f9-salt-reduction-2017-pledge-f10out-of-home-salt-reduction-pledge/ [Accessed 16 April 2018]. 
Department of Health (2017). The availability of gluten free foods on prescription in primary care. Available at: https://assets.publishing.service.gov.uk/government/uploads/system/uploads/attachment d ata/file/604842/Gluten free foods cons.pdf [Accessed 18 Sept 2018]

Department of Health and Social Care (2018). Report of responses following the public consultation on gluten free prescribing. Availability of gluten free food on prescription in primary care. Available at:

https://assets.publishing.service.gov.uk/government/uploads/system/uploads/attachment d ata/file/678181/report of responses - gluten free food prescribing consultation.pdf [Accessed 16 July 2019].

do Nascimento, A. B., Fiates, G. M. R., dos Anjos, A. and Teixeira, E. (2013), "Analysis of ingredient lists of commercially available gluten-free and gluten-containing food products using the text mining technique", International Journal of Food Sciences and Nutrition, Vol. 64 , No. 2, pp. 217-222.

do Nascimento, A., Medeiros Rataichesck Fiates, G., dos Anjos, A. and Teixeira, E. (2014), "Availability, cost and nutritional composition of GF products", British Food Journal, Vol. 116 No. 12, pp.1842-1852.

Drzewiecki, J., Delgado-Licon, E., Haruenkit, R., Pawelzik, E., Martin-Belloso, O., Park, Y.S., Jung, S.T., Trakhtenberg, S. and Gorinstein, S. (2003), "Identification and differences of total proteins and their soluble fractions in some pseudocereals based on electrophoretic patterns", Journal of Agricultural and Food Chemistry, Vol. 51, No. 26, pp. 7798-7804.

Ellaway, A. and Macintyre, S. (2000), "Shopping for food in socially contrasting localities", British Food Journal, Vol. 102, No. 1, pp. 52-59.

Estévez, V., Ayala, J., Vespa, C. and Araya, M. (2016), "The gluten-free basic food basket: a problem of availability, cost and nutritional composition", European Journal of Clinical Nutrition, Vol. 70, No. 10, pp. 1215-1217.

EUFIC (2011). Regulation (EU) no 1169/2011 of the European Parliament and of the council. European Union Food Information Council. Available at: http://eur-lex.europa.eu/legalcontent/EN/TXT/PDF/?uri=CELEX:32011R1169\&from=en [Accessed 11 April 2018].

Fernie, J., Sparks, L. and McKinnon, A. C. (2010), "Retail logistics in the UK: past, present and future", International Journal of Retail \& Distribution Management, Vol. 38, No. 11/12, pp. 894-914.

FAO/WHO (2015). Standard for Foods for Special Dietary Use for Persons Intolerant to Gluten: Codex stan 118-1979. Available at:

http://www.fao.org/input/download/standards/291/CXS 118e 2015.pdf [Accessed 19 April 2018].

FSA (n.d.) European Food Information to Consumers Regulation No 1169/2011 (FIC). Food Standards Agency. Available at: https://www.food.gov.uk/enforcement/regulation/fir/labelling [Accessed 18 April 2018]. 
FSA (2008). UK Salt Reduction Initiative. Food Standards Agency. Available at:

https://www.food.gov.uk/sites/default/files/multimedia/pdfs/saltreductioninitiatives.pdf [Accessed 18 April 2018].

Fry, L., Madden, A. M. and Fallaize, R. (2018), "An investigation into the nutritional composition and cost of gluten-free versus regular food products in the UK", Journal of Human Nutrition and Dietetics, Vol. 31, No. 1, pp.108-120.

Gambus, H., Gambus, F. and Sabat, R. (2002), "The research on quality improvement of gluten-free bread by amaranthus flour addition", Žywnosc, Vol. 2, No. 31, pp. 99-112.

Gobbeti, M. and Gänzle, M., 2013. Handbook on Sourdough Biotechnology. New York: Springer.

Hanci, O. and Jeanes, Y. M. (2018), "Are gluten-free food staples accessible to all patients with coeliac disease?" Frontline Gastroenterology, Vol. 10, No. 3, pp. 222-228.

Hall, N. J., Rubin, G. P. and Charnock, A. (2013), "International and inadvertent nonadherence in adult coeliac disease: A cross-sectional survey", Appetite, Vol. 68, pp. 56-62.

Horstmann, S. W., Lynch, K. M. and Arendt, E. K. (2017), "Starch characteristics linked to gluten-free products", Foods, Vol. 6, No. 4, pp. 29.

IBM Corp (2016). IBM SPSS Statistics for Windows, Version 24.0. Armonk, NY: IBM Corp.

Husby, S., Koletzo, S., Korponay-Szabo, I. R., Mearin, M. L., Phillips, A., Shamir, R. et al. (2012), "European Society for Pediatric Gastroenterology, Hepatology, and Nutrition Guidelines for the diagnosis of coeliac disease", Journal of Pediatric Gastroenterology and Nutrition, Vol. 54, No. 1, pp. 572-573.

Jnawali, P., Kumar, V. and Tanwar, B. (2016), "Celiac disease: Overview and considerations for development of gluten-free foods", Food Science and Human Wellness, Vol. 5, No. 4, pp. 169-176.

Kinsey, L., Burden, S. T. and Bannerman, E. (2008), "A dietary survey to determine if patients with coeliac disease are meeting current healthy eating guidelines and how their diet compares to that of the British general population", European Journal of Clinical Nutrition, Vol. 62, No. 11, pp. 1333-1342.

Kulai, T. and Rashid, M. (2014), "Assessment of nutritional adequacy of packaged glutenfree food products", Canadian Journal of Dietetic Practice and Research, Vol. 75, No. 4, pp. 186-190.

Lacey, C., Clark, B., Frewer, L. and Kuznesof, S. (2016), "Reaching its limits": industry perspectives on salt reduction. British Food Journal, Vol. 118, No. 7, pp. 1610-1624.

Lasztity, R. (1983). Amino Acid Composition and Biological Value of Cereal Proteins. Budapest: Kluwer Academic Publishers.

Lebwohl, B., Murray, J., Rubio-Tapia, A., Green, P. and Ludvigsson, J. (2014), "Predictors of persistent villous atrophy in coeliac disease: a population-based study", Alimentary Pharmacology \& Therapeutics, Vol. 39 No. 5, pp. 488-495. 
Lee, A. R., Ng, D. L., Zivin, J. and Green, P. H. R. (2007), "Economic burden of a gluten-free diet," Journal of Human Nutrition and Dietetics, Vol. 20, No. 5, pp. 423-430.

Lennernäs, M., Fjellstrom, C., Becker, W., Giachetti, I., Schmitt, A., Remaut de Winter, A. and Kearney, M. (1997), "Influences on food choice perceived to be important by nationallyrepresentative samples of adults in the European Union", European Journal of Clinical Nutrition, Vol. 51, No. 2, pp. 8-15.

MacCulloch, K. and Rashid, M. (2014), "Factors affecting adherence to a gluten-free diet in children with celiac disease", Paediatrics \& Child Health, Vol. 19, No. 6, pp.305-309.

Mancebo, C.M., Martínez, M.M., Merino, C., de la Hera, E. and Gómez, M. (2017), "Effect of oil and shortening in rice bread quality: Relationship between rheology and quality characteristics", Journal of Texture Studies, Vol. 48, No. 6, pp. 597-606.

Mariotti, M., Pagani, M.A. and Lucisano, M. (2013), "The role of buckwheat and HPMC on the breadmaking properties of some commercial gluten-free bread mixtures", Food Hydrocolloids, Vol. 30, No. 1, pp. 393-400.

Mazzarella, G. (2015), "Effector and suppressor T cells in celiac disease", World Journal of Gastroenterology, Vol. 21 No. 24, pp. 7349.

Miranda, J., Lasa, A., Bustamante, A., Churruca, I. and Simon, E. (2014), "Nutritional differences between a gluten-free diet and a diet containing equivalent products with gluten. Plant Foods for Human Nutrition, Vol. 69, No. 2, pp. 182-187.

Missbach, B., Schwingshackl, L., Billmann, A., Mystek, A., Hickelsberger, M., Bauer, G. and König, J. (2015), "Gluten-free food database: the nutritional quality and cost of packaged gluten-free foods", PeerJ, Vol. 3, e1337.

Muhammad, H., Reeves, S., Ishaq, S., Mayberry, J. and Jeanes, Y. M. (2017), "Adherence to a gluten free diet is associated with receiving gluten free foods on prescription and understanding food labelling", Nutrients, Vol. 9, No. 7, pp. 705.

MyFitnessPal (2015). Myfitnesspal: Food Search. Available at:

http://www.myfitnesspal.com/food/calorie-chart-nutrition-facts [Accessed 10 December 2017].

Nelsen, D.A. (2002), "Gluten-sensitive enteropathy (celiac disease): more common than you think", American Family Physician, Vol. 66 No. 12, pp. 2259-2266.

NHS (2019). Clinical commissioning groups (CCGs). Available at: https://www.england.nhs.uk/commissioning/who-commissions-nhs-services/ccgs/ [Accessed 17 July 2019].

NHSCC (2018). NHSCC statement on the result of the Department of Health and Social Care consultation on the availability of gluten-free foods on NHS prescription. Available at: https://www.nhscc.org/latest-news/nhscc-statement-on-the-result-of-the-department-ofhealth-and-social-care-consultation-on-the-availability-of-gluten-free-foods-on-nhsprescription/ [Accessed 17 April 2018]. 
NHS Choices (2017). Starchy foods and carbohydrates. Available at: https://www.nhs.uk/Livewell/Goodfood/Pages/starchy-foods.aspx [Accessed 13 April 2018].

Padalino, L., Conte, A. and Del Nobile, M. A. (2016), "Overview of the general approaches to improve gluten-free pasta and bread," Foods, Vol. 5, No. 4, pp. 87.

Public Health England (PHE), 2016. Government Dietary Recommendations: Government recommendations for energy and nutrients for males and females aged 1-18 years and 19+ years. Available at:

https://www.gov.uk/government/uploads/system/uploads/attachment data/file/618167/gov ernment dietary recommendations.pdf [Accessed 28 March 2018].

Robins, G., Akobeng, A., McGough, N., Merrikin, E. and Kirk, E. (2008). A systematic literature review on the nutritional adequacy of a typical gluten-free diet with particular reference to iron, calcium, folate and $B$ vitamins. Available at:

https://www.food.gov.uk/sites/default/files/research-report-gluten-free.pdf [Accessed 10 April 2018].

Sandri, L. T. B., Santos, F. G., Fratelli, C. and Capriles, V. D. (2017), "Development of gluten-free bread formulations containing whole chia flour with acceptable sensory properties", Food Science \& Nutrition, Vol. 5, No. 5, pp. 1021-1028.

Saturni, L., Ferretti, G. and Bacchetti, T. (2010), "The gluten-free diet: Safety and nutritional quality. Nutrients, Vol. 2, No. 1, pp. 16-34.

Simón, E., Larretxi, I., Churruca, I., Lasa, A., Bustamante, M.A., Navarro, V., Fernández-Gil. and Miranda, J. (2017). Nutritional and Analytical Approaches of Gluten-Free Diet in Celiac Disease. Springer International Publishing, pp. $1-94$.

Singh, J. and Whelan, K. (2011), "Limited availability and higher cost of gluten-free foods", Journal of Human Nutrition and Dietetics, Vol. 24, No. 5, pp. 479-486.

Smith, P. (2010). Gluten-free food supplier faces competition from the supermarkets. The Telegraph online, 03 May. Available at:

https://www.telegraph.co.uk/finance/businessclub/7674019/Gluten-free-food-supplier-facescompetition-from-the-supermarkets.html [Accessed 14 April 2018].

Stevens, L. and Rashid, M. (2008), "Gluten-free and regular foods: A cost comparison", Canadian Journal of Dietetic Practice and Research, Vol. 69, No. 3, pp. 147-150.

Theethira, T., Dennis, M. and Leffler, D. (2014), "Nutritional consequences of celiac disease and the gluten-free diet", Expert Review of Gastroenterology \& Hepatology, Vol. 8 No. 2, pp. 123-129.

Thompson, T. (2000), "Folate, iron and dietary fiber contents of the gluten-free diet", Journal of the Academy of Nutrition and Dietetics, Vol. 100, No. 11, pp. 1389-1396.

Wang, K., Lu, F., Li, Z., Zhao, L. and Han, C. (2017), "Recent developments in gluten-free bread baking approaches: a review", Food Science and Technology, Vol. 37, No. 1, pp. 1-9.

Webb, G. P. (2013). Nutrition: Maintaining and improving health. $4^{\text {th }}$ ed. Boca Raton: CRC Press. 
WHO (2004). Global Strategy on Diet, Physical Activity and Health. Geneva: World Health Organisation. Available at: http://www.who.int/dietphysicalactivity/strategy/eb11344/strategy english web.pdf [Accessed 17 April 2018].

WHO (2016). Salt reduction: fact sheet. Geneva: World Health Organisation. Available at: http://www.who.int/mediacentre/factsheets/fs393/en/ [Accessed 19 April 2018].

Wieser, H. (2007), "Chemistry of gluten proteins", Food Microbiology, Vol. 24, No. 2, pp. 115-119.

Wright, H., 2017. Availability of gluten-free products on NHS prescription: Consultation response form. Available at:

https://www.rpharms.com/Portals/0/RPS\%20document\%20library/Open\%20access/Consult ations/June\%202017/consdoc3991.pdf [Accessed 14 April 2018].

Wu, J. H. Y., Neal, B., Trevena, H. and Dunford, E. (2015), "Are gluten free foods healthier than non-gluten free foods? An evaluation of supermarket products in Australia", British Journal of Nutrition, Vol. 114, No. 3, pp. 448-454. 